\title{
CALIBRATION OF SURFACE CONTAMINATION MONITORS FOR THE DETECTION OF IODINE INCORPORATION IN THE THYROID GLAND
}

\author{
C. Bailat*, T. Buchillier, S. Baechler and F. Bochud \\ Institute of Radiation Physics, Lausanne, Switzerland \\ *Corresponding author: claude.bailat@chuv.ch
}

\begin{abstract}
In Switzerland, individuals exposed to the risk of activity intake are required to perform regular monitoring. Monitoring consists in a screening measurement and is meant to be performed using commonly available laboratory instruments. More particularly, iodine intake is measured using a surface contamination monitor. The goal of the present paper is to report the calibration method developed for thyroid screening instruments. It consists of measuring the instrument response to a known activity located in the thyroid gland of a standard neck phantom. One issue of this procedure remains that the iodine radioisotopes have a short half-life. Therefore, the adequacy and limitations to simulate the short-lived radionuclides with so-called mock radionuclides of longer half-life were also evaluated. In light of the results, it has been decided to use only the appropriate iodine sources to perform the calibration.
\end{abstract}

\section{INTRODUCTION}

Handling radioactive substances in liquid or powder form can involve a risk of activity intake through inhalation or ingestion. In Switzerland as well as many other countries, exposed individuals are legally required by an ordinance to perform regular monitoring $^{(1)}$. Additionally, a routine monitoring consisting in a rough measurement, called a screening measurement, whose goal is to detect a potential activity intake, is required in Switzerland ${ }^{(2,3)}$. If the result is negative, it is assumed that the person is not contaminated. Alternatively, if the screening test is positive, a more precise measurement is then conducted by an approved dosimetry service for a precise intake evaluation ${ }^{(2,4)}$. The committed dose resulting from an internal contamination is then calculated according to the ICRP recommendations, which also requires the establishment of such routine monitoring programme.

The screening measurement specified by the Swiss ordinance is meant to be performed using commonly available laboratory instruments, which should be metrologically traceable to international standards. Practically, depending on the radionuclide, the screening tests are performed using surface contamination or dose rate monitors. Screening measurements allows exposed individuals to perform incorporation monitoring on their own. Other techniques such as whole-body counters, typical of an approved dosimetry service ${ }^{(5)}$, or imaging plates ${ }^{(6)}$, are not daily accessible to the majority of the exposed personnel.

The screening measurement for iodine intake is performed by measuring the activity of the thyroid using a surface contamination monitor at throat level. The screening threshold is set by the ordinance at $1400 \mathrm{~Bq}$ for ${ }^{123} \mathrm{I}, 1300 \mathrm{~Bq}$ for ${ }^{125} \mathrm{I}$ and $2000 \mathrm{~Bq}$ or

${ }^{131} \mathrm{I}$. Even if the required accuracy for a thyroid screening test is not critical, typically $\pm 50 \%$, the large geometry difference between the measurement of surface contaminations and of a thyroid implies that the dedicated contamination monitor must have undergone an adequate screening-type calibration.

The incorporation measurement conducted by an approved dosimetry service has a higher degree of complexity, takes a longer acquisition time, and must measure accurately the incorporated activity. The description of the incorporation measurement will not be presented here.

The goal of the present paper is to report the calibration methods developed and tested for thyroid screening measurements using commonly used contamination monitors.

\section{MATERIAL AND METHODS}

\section{Material}

A neck phantom built with $950 \mathrm{~kg} \mathrm{~m}^{-3}$ polyethylene is used in order to simulate a contaminated thyroid. The phantom consists of a polyethylene cylinder (140 $\mathrm{mm}$ diameter $\times 160 \mathrm{~mm}$ height) bored with two holes $(28 \mathrm{~mm}$ diameter $\times 64 \mathrm{~mm}$ height) for two 20 $\mathrm{ml}$ vials representing the thyroid glands (Figure 1). The Swiss authorities require to use the neck phantom, which simulates the activity in thyroid glands, and takes into account the scattered radiation and attenuation of gamma and $\mathrm{X}$ rays in the tissues between the thyroid and the detector. Considering a human neck as being simply a $1 \mathrm{~cm}$ layer of soft-tissue may seem too simplistic. 


\section{BAILAT ET AL.}

However, it reflects reasonably accurately the average human being within the normal variation of the human $^{(2)}$.

Reference radioactive solutions were conditioned in polyethylene liquid scintillation counting vials of $20 \mathrm{ml}$ and certified. The typical reference activities of ${ }^{123} \mathrm{I},{ }^{125} \mathrm{I}$ and ${ }^{131} \mathrm{I}$ were of a few tens of kiloBecquerel. The vials activity was measured by gamma spectrometry using an HPGe gamma-X Ortec detector (relative efficiency $23 \%$ ). An efficiency curve established for this type of vial and traceable to national activity standards was used for ${ }^{123} \mathrm{I},{ }^{131} \mathrm{I}$ and their simulators ${ }^{57} \mathrm{Co}$ and ${ }^{133} \mathrm{Ba}$. For ${ }^{125} \mathrm{I}$ and ${ }^{129} \mathrm{I}$, a detector calibration with a reference solution of ${ }^{125} \mathrm{I}$ from the former Laboratoire de métrologie des rayonnements ionisants (LMRI) has been carried out in terms of count rate in the peaks per unit activity. Corrections for the different gamma intensities and self-attenuation have been taken into account when necessary.

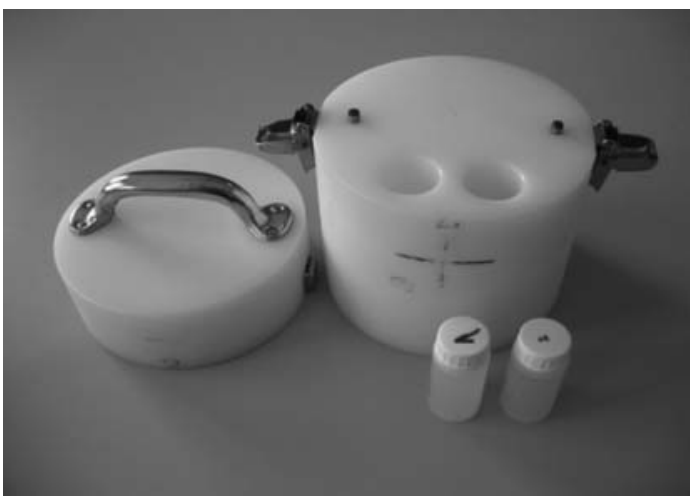

Figure 1. Polyethylene neck phantom bored with two holes for $20 \mathrm{ml}$ radioactive vials.
The activity expanded uncertainties $(k=2)$ are $3 \%$ for ${ }^{57} \mathrm{Co},{ }^{123} \mathrm{I},{ }^{131} \mathrm{I}$ and ${ }^{133} \mathrm{Ba}, 6 \%$ for ${ }^{125} \mathrm{I}$ and $10 \%$ for ${ }^{129} \mathrm{I}$.

Each tested surface contamination monitor was previously calibrated to measure adequately surface contamination according to national and international standards ${ }^{(7-10)}$.

Over 15 different models of surface contamination monitors have been calibrated. In this study, as many as possible instruments of each model were taken into account. Up to 24 instruments of each model have been calibrated. The type of detector most often encountered was the proportional counters. Some technical characteristics of the instruments types are given in Table 1 . The results are analysed and averaged according to the instrument types.

Geiger-Müller-based counters were found not adequate for thyroid screening because of their low efficiency and are not taken into account in this study.

\section{Calibration procedure}

\section{Calibration using iodine reference solutions}

The procedure consists of measuring the response of the instrument to a known activity located in the thyroid glands of the neck phantom.

The two polyethylene vials containing $20 \mathrm{ml}$ of reference iodine solution are positioned inside the phantom holes. The contamination monitor is then aligned with the phantom centre. Rectangular detectors are oriented as they would be used in practice. Ten independent activity readings of the radioactive solutions are taken using the most appropriate time constant on the instrument for a good observable count rate. The exact time of the measurements is recorded to take into account the radioactive decay

Table 1. Characteristics of typical calibrated instruments.

\begin{tabular}{|c|c|c|}
\hline Type & Detector & Characteristics \\
\hline $\mathrm{N} 2$ & $\mathrm{NaI}$ & $\varnothing 23 \times 1 \mathrm{~mm}, 14 \mathrm{mg} \mathrm{cm}^{-2} \mathrm{Al}$ window, for $E=10-60 \mathrm{keV}$ \\
\hline $\mathrm{N} 2^{\prime}$ & $\mathrm{NaI}$ & Same detector as N2, different electronics \\
\hline N3 & $\mathrm{NaI}$ & $\varnothing 32 \times 2.5 \mathrm{~mm}, 14 \mathrm{mg} \mathrm{cm}^{-2} \mathrm{Al}$ window, for $E=15-250 \mathrm{keV}$ \\
\hline N5 & $\mathrm{NaI}$ & $\varnothing 25 \times 38 \mathrm{~mm}$, window not specified, for $E>25 \mathrm{keV}$ \\
\hline N6 & $\mathrm{NaI}$ & Same detector as N3, different electronics \\
\hline N7 & $\mathrm{NaI}$ & $\varnothing 25 \times 2 \mathrm{~mm}, 7 \mathrm{mg} \mathrm{cm}^{-2} \mathrm{Al}$ window, $E$ not specified \\
\hline N8 & $\mathrm{NaI}$ & $\varnothing 25 \times 25 \mathrm{~mm}$, window and $E$ not specified \\
\hline N9 & $\mathrm{NaI}$ & No specifications available \\
\hline N10 & $\mathrm{NaI}$ & $\varnothing 50 \times 50 \mathrm{~mm}$, window and $E$ not specified \\
\hline P1 & proportional counter & $100 \mathrm{~cm}^{2}$, Xe filled, $5 \mathrm{mg} \mathrm{cm}^{-2} \mathrm{Ti}$ window \\
\hline $\mathrm{P} 2$ & proportional counter & $200 \mathrm{~cm}^{2}$, Xe filled, $5 \mathrm{mg} \mathrm{cm}^{-2} \mathrm{Ti}$ window \\
\hline P3 & proportional counter & same detector as $\mathrm{P} 2$, different electronics \\
\hline P4 & proportional counter & $233 \mathrm{~cm}^{2}$, Xe filled, $5 \mathrm{mg} \mathrm{cm}^{-2}$ Ti window \\
\hline $\mathrm{S} 1$ & plastic scintillator & $170 \mathrm{~cm}^{2}$ plastic scintillator coated with $\mathrm{ZnS}$ \\
\hline
\end{tabular}


of the reference source. The same procedure is repeated without source in the phantom to determine the background. It is in a sense a measurement of a blank. The average net count rate is calculated together with its experimental standard deviation.

The contamination monitor efficiency $S(\mathrm{~s} \mathrm{kBq})^{-1}$ for a given radionuclide is calculated using the following equation:

$$
S=\frac{M_{\text {net }}}{A_{\text {ref }}},
$$

where $M_{\text {net }}$ is the net count rate of the monitor in $\mathrm{s}^{-1}$ after subtraction of the background, $A_{\text {ref }}$ is the activity of the reference source in kiloBecquerel at the measurement date.

The count rate corresponding to the screening threshold (given in terms of activity in the ordinance) is calculated. The instrument is judged suitable for screening test if this value is higher than three times the standard deviation of the background. Otherwise the instrument is judged not appropriate for screening purpose.

\section{Calibration using mock solutions}

One issue of this calibration procedure is that the iodine radioisotopes $\left({ }^{123} \mathrm{I},{ }^{125} \mathrm{I}\right.$ and $\left.{ }^{131} \mathrm{I}\right)$ have short half-lives; and it would be beneficial to be able to use so-called mock radionuclides of longer half-life.

The substitution of the radionuclide of interest is justified only if the detector response remains comparable. Hence the choice of a simulating radionuclide is based on the photon emissions which must be of similar energies than the iodine radioisotope. Beta emissions need not to be considered as they are completely absorbed in the solution, the vial and the phantom. The effects of different bremsstrahlung intensity as well as the losses of counting due to true coincidences are neglected.

When iodine is simulated with a mock solution, the difference in photonic emissions between the simulated and simulating solution was taken into account. The apparent activity, $A_{\mathrm{app}}$, of a simulating radionuclide equivalent to a simulated radionuclide is calculated by the product of the mock solution activity, $A_{\text {ref }}$, and a correction factor $f_{\text {int }}$, which takes into account the attenuation in the phantom as a function of the emission energies. The relation between apparent and reference activity can be written then:

$$
A_{\text {app }}=\frac{\sum_{i} \mathrm{e}^{-\mu_{i} x} b_{i} I_{i, \text { sim }}}{\sum_{j} \mathrm{e}^{-\mu_{j} x} b_{j} I_{j, \text { orig }}} \cdot A_{\text {ref }}=f_{\text {int }} \cdot A_{\text {ref }},
$$

where $\mu$ is the linear attenuation coefficient in the phantom material, $x$ the mean distance inside the phantom before the detector, $b_{i}$ the build-up factor of a given photon energy and $I_{i}$ the emission intensity of a given photon energy $i$.

Only gamma and X-ray lines with intensities $>1 \%$ are considered in the calculation. Also, the lines with energies below $10 \mathrm{keV}$ are neglected as they are almost entirely absorbed before reaching the detector. Photons emerging from Compton scattering within the solid angle of the detector can also be detected, and build-up factors were estimated using MicroShield ${ }^{\circledR}$ v5.05. The geometry was simplified into cylindrical sources and shielding. The thickness of the shielding were varied from 1 to $3 \mathrm{~cm}$ and the values of $f_{\text {int }}$ are given in Table 2. The influence of the value of the absorption mean distance on the correction factor remains under $10 \%$.

A thickness of $1 \mathrm{~cm}$ lies between the vial and the detector. The absorption mean distance was fixed equal to $2 \mathrm{~cm}$ in order to take into account that the vial has a diameter of $2.7 \mathrm{~cm}$ and that some emissions will not impinge the detector orthogonally.

These choices would be too limiting in the case of an incorporation measurement, but remain acceptable for screening instruments calibration. For a more precise determination of the various parameters, Monte Carlo calculations would be necessary.

The efficiency of the instrument using a mock radionuclide $S_{\text {sim }}$ can be determined by replacing $A_{\text {ref }}$ by $A_{\text {app }}$ in equation (1). In order to evaluate the suitability of the method, the measurements were done with mock as well as iodine solutions. The ratio of the obtained efficiencies $S_{\text {sim }} / S$ is used to analyse the adequacy of the method and its variability is an estimate of the repeatability of the method for each instrument type and model.

Table 2. Correction factors for various absorption mean distance $x$ to take into account the difference of photonic

\begin{tabular}{|c|c|c|c|}
\hline Simulated & Simulating & $\begin{array}{l}\text { Correction } \\
\text { factor }\end{array}$ & $\begin{array}{c}\text { Uncertainty } \\
\quad(k=2)\end{array}$ \\
\hline \multicolumn{4}{|l|}{$x=1 \mathrm{~cm}$} \\
\hline${ }^{123} \mathrm{I}$ & ${ }^{57} \mathrm{Co}$ & 0.56 & 0.07 \\
\hline${ }^{125} \mathrm{I}$ & ${ }^{129} \mathrm{I}$ & 0.52 & 0.04 \\
\hline${ }^{131} \mathrm{I}$ & ${ }^{133} \mathrm{Ba}$ & 2.96 & 0.11 \\
\hline \multicolumn{4}{|l|}{$x=2 \mathrm{~cm}$} \\
\hline${ }^{123} \mathrm{I}$ & ${ }^{57} \mathrm{Co}$ & 0.65 & 0.07 \\
\hline${ }^{125} \mathrm{I}$ & ${ }^{129} \mathrm{I}$ & 0.55 & 0.04 \\
\hline${ }^{131} \mathrm{I}$ & ${ }^{133} \mathrm{Ba}$ & 3.04 & 0.17 \\
\hline \multicolumn{4}{|l|}{$x=3 \mathrm{~cm}$} \\
\hline $125 \mathrm{I}$ & ${ }^{129} \mathrm{CO}$ & 0.72 & 0.08 \\
\hline${ }^{131} \mathrm{I}$ & ${ }^{133} \mathrm{P}$ & 0.58 & 0.04 \\
\hline & $\mathrm{Ba}$ & 2.94 & 0.11 \\
\hline
\end{tabular}
emissions between the simulated and simulating radionuclide. 


\section{RESULTS AND DISCUSSION}

\section{Calibration using iodine reference solutions}

The efficiencies obtained with the iodine reference solutions are given in Table 3. Results have been averaged for each instrument type. Proportional counters $\mathrm{P} 1-\mathrm{P} 4$ show a good uniformity of efficiencies. Instrument Type P2 presents more uniform values than the older, discontinued Type P1. There is no clear correlation of the efficiency with detector size for proportional counters. Plastic scintillator counters S1 show higher efficiencies than proportional counters. Efficiencies of instruments based on NaI crystals are strongly dependant on the detector dimensions. Instruments type $\mathrm{N} 3(\varnothing 32 \times 2.5 \mathrm{~mm})$ and N5 $(\varnothing 25 \times 38 \mathrm{~mm})$ illustrate this dependence: when responses are similar to ${ }^{123} \mathrm{I}(160 \mathrm{keV}), \mathrm{N} 3$ has a better response to ${ }^{125} \mathrm{I}(30 \mathrm{keV})$ and $\mathrm{N} 5$ a better one to ${ }^{131} \mathrm{I}(360 \mathrm{keV})$. The performances of a NaI instrument are also affected by the electronics to which it is connected, and by the settings like highvoltage bias and lower level discriminator. This is noticeable looking at N3 and N6 which are different electronics based on the same NaI crystal. The high variability for a given type is also attributed to the influence of the settings, especially for the low energies of ${ }^{125} \mathrm{I}$.

The contamination monitors were found suitable for the screening test, except for Geiger-Müllerbased counters due to their low efficiency. The other counter types were found to have generally a counting efficiency higher than $10(\mathrm{~s} \mathrm{kBq})^{-1}$. The screening threshold for the iodine radionuclides will induce over 10 counts per seconds on most instruments, which is enough to be measured in practice. In general, the NaI-based detectors had higher efficiencies and are therefore the most suitable for such screening tests.

\section{Calibration using mock solutions}

The results of the simulation method are described by the ratio of the efficiency obtained using the mock solution and the efficiency with the iodine reference solution. Table 4 shows the ratios averaged for each instrument type. Values close to 1 indicate that the use of a simulating radionuclide for the calibration is well approximated with the assumptions of this study. For ${ }^{123} \mathrm{I}$, this is the case for proportional counters $\mathrm{P} 2-\mathrm{P} 4$, while NaI instruments show larger variations (ratio from 1.2 to 1.6) and plastic scintillators are far away $(0.25)$. For ${ }^{125} \mathrm{I}$, the agreement between the two methods is better (1.01.8). For ${ }^{131} \mathrm{I}$, the ${ }^{133} \mathrm{Ba}$ simulation is generally not valid (1.1-4.9). Although the main gamma energies are similar for ${ }^{131} \mathrm{I}$ and ${ }^{133} \mathrm{Ba}$, this latter has intense $\mathrm{X}$-ray emissions which contribute strongly as noticed in Table 2. The simulation of ${ }^{131} \mathrm{I}$ by ${ }^{133} \mathrm{Ba}$ is valid only for thick NaI crystals because the probability of detection of a photon impinging on the detector approaches 1 and is hence less dependent on its energy.

Another way to validate the simulation method would be to find a universal correction factor for a detector type or at least a model. Looking at Tables 3 and 4 , the relative standard deviation mirrors the variability of the efficiencies and efficiencies ratio. Proportional counters seemed a bit more uniform, but still suffer of a high variability in order to infer with confidence a universal correction factor for all proportional counters. The variability of other detector types is even higher. A correction

Table 3. Calibration results using ${ }^{123} \mathrm{I},{ }^{125} \mathrm{I}$ and ${ }^{131} \mathrm{I}$ radioisotopes: efficiency, standard deviation and number of calibrated instruments of each type.

\begin{tabular}{|c|c|c|c|c|c|c|c|c|c|}
\hline Type & $\begin{array}{l}\text { Averaged } S_{123} \mathrm{I} \\
\quad(\mathrm{s} \mathrm{kBq})^{-1}\end{array}$ & $\begin{array}{l}\text { Standard } \\
\text { deviation }\end{array}$ & $n$ & $\begin{array}{l}\text { Averaged } S_{125} \mathrm{I} \\
\quad(\mathrm{s} \mathrm{kBq})^{-1}\end{array}$ & $\begin{array}{l}\text { Standard } \\
\text { deviation }\end{array}$ & $n$ & $\begin{array}{l}\text { Averaged } S_{131} \mathrm{I} \\
\quad(\mathrm{s} \mathrm{kBq})^{-1}\end{array}$ & $\begin{array}{l}\text { Standard } \\
\text { deviation }\end{array}$ & $n$ \\
\hline P1 & 13.4 & $16 \%$ & 16 & 16.0 & $20 \%$ & 22 & 2.4 & $22 \%$ & 16 \\
\hline P2 & 12.6 & $13 \%$ & 17 & 13.4 & $4 \%$ & 24 & 3.0 & $6 \%$ & 21 \\
\hline P3 & 11.7 & $2 \%$ & 3 & 13.5 & $5 \%$ & 5 & 2.5 & $10 \%$ & 4 \\
\hline P4 & 15.4 & $6 \%$ & 4 & 17.3 & - & 1 & 3.2 & $7 \%$ & 7 \\
\hline $\mathrm{S} 1$ & 19.1 & $25 \%$ & 2 & 26.0 & $31 \%$ & 2 & 3.9 & $3 \%$ & 2 \\
\hline N2 & 9.0 & $34 \%$ & 9 & 9.3 & $62 \%$ & 17 & 2.6 & $35 \%$ & 9 \\
\hline $\mathrm{N} 2^{\prime}$ & 8.0 & - & 1 & 9.5 & - & 1 & 2.1 & - & 1 \\
\hline N3 & 22.9 & $35 \%$ & 6 & 20.7 & $30 \%$ & 8 & 7.1 & $16 \%$ & 7 \\
\hline N5 & 24.7 & - & 1 & 10.5 & - & 1 & 17.3 & - & 1 \\
\hline N6 & - & - & 0 & 33.7 & $8 \%$ & 8 & & - & 0 \\
\hline N7 & - & - & 0 & 17.4 & - & 1 & & - & 0 \\
\hline N8 & - & - & 0 & 5.5 & - & 1 & 11.8 & - & 1 \\
\hline N9 & 103.5 & - & 1 & 53.6 & $2 \%$ & 2 & 64.3 & - & 1 \\
\hline N10 & 65.7 & $12 \%$ & 2 & 19.1 & $6 \%$ & 3 & 30.1 & $5 \%$ & 3 \\
\hline
\end{tabular}


CALIBRATION OF SURFACE CONTAMINATION MONITORS

Table 4. Calibration results using mock radioisotopes: efficiency ratio $S_{\text {sim }} / S$, standard deviation and number of calibrated instruments of each type.

\begin{tabular}{|c|c|c|c|c|c|c|c|c|c|}
\hline Type & $\begin{array}{l}\text { Averaged } \\
\text { Efficiencies } \\
\text { ratio } \\
S_{{ }^{57} \mathrm{Co}} / S_{{ }^{123} \mathrm{I}}\end{array}$ & $\begin{array}{l}\text { Standard } \\
\text { deviation }\end{array}$ & $n$ & $\begin{array}{c}\text { Averaged } \\
\text { Efficiencies } \\
\text { ratio } \\
S_{129} / S_{125}\end{array}$ & $\begin{array}{l}\text { Standard } \\
\text { deviation }\end{array}$ & $n$ & $\begin{array}{c}\text { Averaged } \\
\text { Efficiencies } \\
\text { ratio } \\
S_{133} \mathrm{Ba} / S_{131}\end{array}$ & $\begin{array}{l}\text { Standard } \\
\text { deviation }\end{array}$ & $n$ \\
\hline P1 & 0.68 & $11 \%$ & 16 & 1.11 & $9 \%$ & 20 & 4.90 & $14 \%$ & 16 \\
\hline P2 & 0.90 & $12 \%$ & 17 & 1.18 & $7 \%$ & 24 & 3.88 & $5 \%$ & 21 \\
\hline P3 & 0.87 & $9 \%$ & 3 & 1.17 & $6 \%$ & 5 & 4.70 & $9 \%$ & 4 \\
\hline P4 & 0.87 & $13 \%$ & 4 & 1.19 & - & 1 & 4.90 & $4 \%$ & 7 \\
\hline $\mathrm{S} 1$ & 0.25 & $28 \%$ & 2 & 0.96 & $32 \%$ & 2 & 3.62 & $8 \%$ & 2 \\
\hline N2 & 1.44 & $42 \%$ & 8 & 1.78 & $59 \%$ & 17 & 4.22 & $17 \%$ & 9 \\
\hline $\mathrm{N} 2^{\prime}$ & 1.21 & - & 1 & 1.40 & - & 1 & 4.47 & - & 1 \\
\hline N3 & 1.50 & $47 \%$ & 6 & 1.65 & $23 \%$ & 8 & 3.58 & $5 \%$ & 7 \\
\hline N5 & 1.60 & - & 1 & 1.63 & - & 1 & 1.48 & - & 1 \\
\hline N6 & - & - & 0 & 1.20 & $16 \%$ & 8 & - & - & 0 \\
\hline N7 & - & - & 0 & 1.68 & - & 1 & - & - & 0 \\
\hline N8 & - & - & 0 & 1.75 & - & 1 & 1.39 & - & 1 \\
\hline N9 & 1.37 & - & 1 & 1.50 & $2 \%$ & 2 & 1.39 & - & 1 \\
\hline N10 & 1.57 & - & 1 & 1.28 & $30 \%$ & 2 & 1.12 & $57 \%$ & 2 \\
\hline
\end{tabular}

factor for each model of detector might be calculated at the price of accuracy, but its validity makes no sense, when the variability of the efficiency among the same models is already high (Table 3). Furthermore, this factor would have to be measured again for each new model or modification of the electronics.

\section{CONCLUSIONS}

Most instrument types used in Switzerland for thyroid screening were calibrated using ${ }^{123} \mathrm{I},{ }^{125} \mathrm{I}$ and ${ }^{131}$ I sources. The use of simulating radioisotopes, respectively, ${ }^{57} \mathrm{Co},{ }^{129} \mathrm{I}$ and ${ }^{133} \mathrm{Ba}$, was tested as well. The proportional counters showed uniform responses for a set model, but $\mathrm{NaI}$ crystal probe instruments are more prone to variability for a particular model. NaI-based counters have however higher efficiencies.

On a metrological level, the calibrations performed with simulating radionuclides were not convincing. The variability was too important between instrument types as well as for a given type, preventing the use of a correction factor tailored for a specific type of instrument or even a model.

In light of the results, it has been decided to use only the appropriate iodine sources to perform the calibration. In order to reduce the high costs implied for manufacturing such short-lived radionuclide standards, the calibrations are performed during defined periods and the laboratories are required to subscribe in advance.

\section{REFERENCES}

1. Swiss ordinance on radiation protection. SR814.501 (1994).

2. Baechler, S. et al. Routine individual monitoring of internal exposure for nuclear medicine workers in Switzerland. Radiat. Prot. Dosim. this issue.

3. Frei, D. et al. Integration of external and internal dosimetry in switzerland. Radiat. Prot. Dosim. 125, 47-51 (2007).

4. Lopez Ponte, M. A., Castellani, C. M., Currivan, L., Falk, R., Olko, P. and Wernli, C. Individual monitoring for internal exposure in europe and the integration of dosimetric data. Radiat. Prot. Dosim. 112, 69-119 (2004).

5. Boschung, M., Eikenberg, J. and Wernli, C. Incorporation measurements in Switzerland: the approved internal dosimetry service at PSI. Radiat. Prot. Dosim. 105, 351-354 (2003).

6. Masahiro, H., Takuya, S., Yoshimune, O. and Kunihide, N. Feasibility of in vivo thyroid 1311 monitoring with an imaging plate. Appl. Radiat. Isot. 55, 513-516 (2001).

7. International Atomic Energy Agency. Calibration of radiation protection monitoring instruments. Technical Reports Series No. 16. IAEA (2000).

8. International Organization for Standardization. Evaluation of surface contamination. ISO 7503-1:1988 and ISO 7503-3:1996.

9. International Organization for Standardization. Reference sources for the calibration of surface contamination monitors. ISO 8769:1988 and ISO 8769-2:1996.

10. International Electrotechnical Commission. Alpha, Beta and Alpha-Beta Contamination Meters and Monitors. IEC, 325 (1995). 